\title{
Incendiadas polémicas no Quebeque Notas de uma europeia
}

\author{
Ana Pais
}

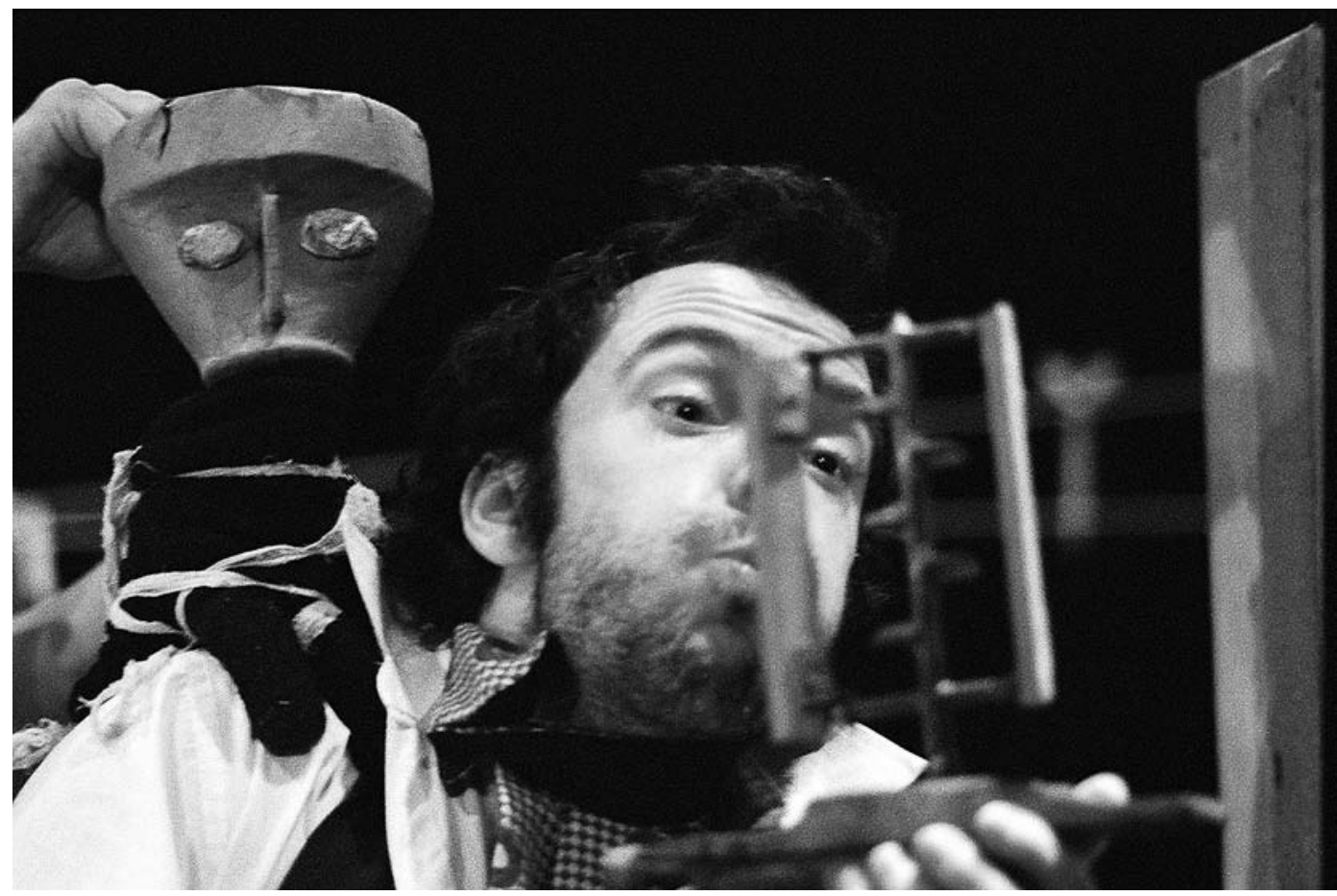

Persée

texto e enc. Olivier Ducas Mathieu Gosselin

e Francis Monty,

Théâtre de la Pire Espèce, Quebeque, 2006

(Francis Monty),

fot. Émilie Bélanger.

No Quebeque, faz-se e vê-se teatro com entusiasmo. Uma das razões para tal enlevo radica na função de espelhamento crítico que o teatro vem adquirindo naquela sociedade. Nas palavras do crítico Hervé Guay, a partir da sua invenção por Michel Tremblay, em 1968, "o teatro moderno do Quebeque quis-se espelho da existência de um povo" (Guay 2005:147, trad. minha). Este "povo", pertencente à monarquia constitucional canadiana (baseada no modelo inglês), afirma-se por uma especificidade cultural, revelada no teatro. Nada alheia ao contexto político das lutas independistas, balizado por dois referendos (1980 e 1995), a tendência identitária do teatro do Quebeque das últimas duas décadas do século passado surge como estratégia preferencial de construção ou reforço de traços de uma identidade particular.

Claramente, os quebequenses estimulam a recordação da herança linguística e cultural francófona com o hábil propósito de enfatizar um distanciamento face ao cerco anglófono. Por isso, os laços com a França, sobretudo a nível académico e cultural, têm vindo a intensificar-se ainda que isso não se traduza na difusão do panorama artístico do Quebeque na Europa, à excepção de nomes esparsos como Robert Lepage ou Marie Chouinard. E Céline Dion, claro. No passado mês de Maio, tive o privilégio de assistir à oitava edição do Carrefour International de Théâtre de Québec e procurarei fazer aqui um breve comentário aos espectáculos que se destacaram aos olhos de uma visitante europeia.

0 Carrefour tem lugar bienalmente desde há 16 anos a esta parte, na cidade de Quebeque. Na direcção artística desde o início, a dupla Marie Gignac e Brigitte Haentjiens não se tem poupado a esforços no que respeita à fidelização de públicos. Tradicionalmente dedicada ao teatro francófono, a última edição do Carrefour não fugiu à regra, apesar de o seu orçamento limitado permitir o convite a quatro produções europeias. A língua exclusiva dos espectáculos foi o francês (muitos legendados em inglês) e, segundo o texto da direcção do festival, a questão da busca identitária, fosse ela pessoal, colectiva ou universal, atravessava a programação. Estas opções (ou coincidências, segundo o mesmo texto) definem, à partida, um território cultural de expectativas também elas identitárias, responsáveis porventura pela sedimentação daquele público específico.

Dentre seis espectáculos quebequenses e três apresentações de laboratórios realizados por jovens encenadores, um dos mais esperados era Tout comme elle, assinado por Brigitte Haentjiens (renomada encenadora). Cinquenta actrizes em palco expõem a complexidade e os 


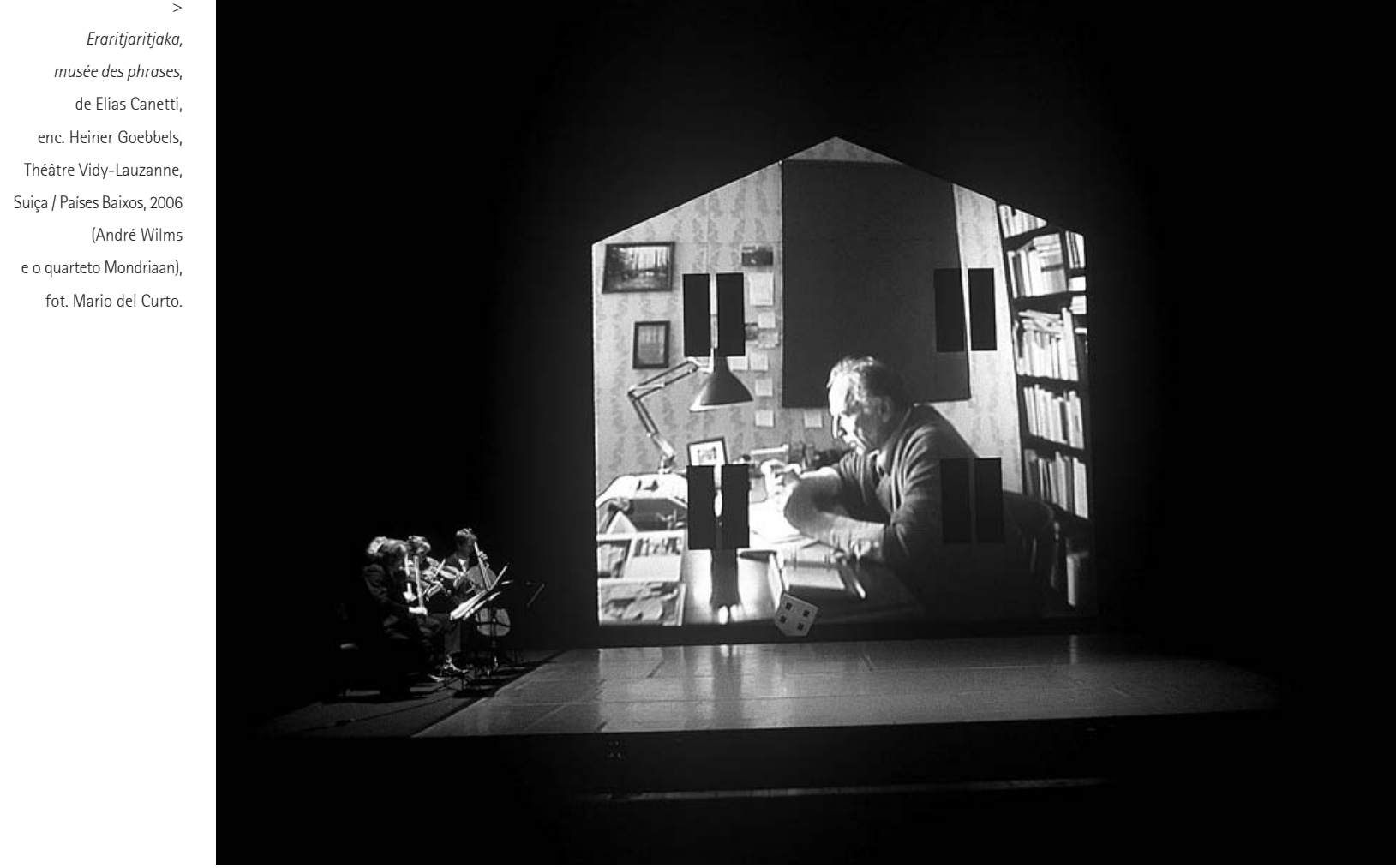

tabus das relações mãe/filha, numa partitura de corpo, texto, dança e canto. Infelizmente, não me foi possivel assistir a este espectáculo. Fica a nota da sua singularidade.

Eventualmente derivado da sua linguagem universalista (se ela for possivel), o espectáculo de teatro de objectos da companhia Théâtre de la Pire Espèce, de Montréal, foi, para os meus olhos europeus, a mais surpreendente rigorosa e estimulante produção quebequense do festival. Fundada por Olivier Ducas e Francis Monty, a companhia conheceu sucesso imediato com a sua versão particular de Rei Ubu, intitulada Ubu sur la table (1998). Ao Carrefour trouxeram uma salutar invenção a partir do mito de Perseu Persée (2005). No início do século XX, três arqueólogos (os dois fundadores e Mathieu Gosselin) tentam provar à comunidade científica a existência real de Perseu através dos objectos raros que vão descobrindo e animando.

A quimera não chega a concretizar-se e a dúvida existencia é relançada sobre os próprios arqueólogos/actores. Sabendo que o teatro de objectos se pauta, justamente, por criar entidades imaginadas em objectos por meio de subtis mudanças no aspecto ou funcionalidade dos mesmos poderemos facilmente perceber que a estratégia de abordagem do mito grego revela uma inteligência e autoreflexividade criativas assinaláveis. 0 enquadramento ficcional dos objectos "animados", da marioneta ou do jogo clownesco deste Perseé numa exploração arqueológica cria um estimulante diálogo entre os níveis da fábula: a busca de uma explicação da origem na mitologia, no teatro, no actor e no individuo. Mais do que a mestria técnica, é este aspecto de excelência de pensamento cénico que distingue este trabalho da média do teatro de objectos, sem descurar, todavia, o aspecto lúdico e de relação directa com o público.

Um bom exemplo da ironia discreta de Persée é o seu início. Na boca de cena, em frente da pequena tenda/cena onde se desenrolarão as cenas "arqueológicas", os três intérpretes e autores apresentam-se (como intérpretes e autores) e perguntam ao público se conhece o mito de Perseu (dedos no ar, risos, etc.). Dispondo-se a actualizar os dados do espectador, iniciam uma projecção de diapositivos sobre a tela que fecha, temporariamente, a tenda/cena, acompanhada por uma narração do mito. Mas, de tal forma o mito é imbrincado e o actor o narra com velocidade (apesar das pausas e repetições cómicas para garantir que todos percebiam a genealogia das personagens), que provavelmente ninguém terá conseguido ficar com ideia alguma sobre ele. Com este artificio simples se estabelece o ponto de partida, de ironias múltiplas, para a entrada no mundo dos objectos de Perseu e na moral da história: todos terão acesso ao espectáculo, com ou sem conhecimendo do mito, pois a sua linguagem cénica disso se encarregará.

No pólo oposto de Persée em termos de aparato cénico, a mais recente criação do compositor suiço Heiner Goebbels, Eraritjaritjaka - Musée des Phrases, mostrou como nas grandes produções, sobretudo naquelas em que se recorre à tecnologia em grande escala, a simplicidade ganha à pura exibição técnica. Concebido como uma partitura multimédia, isto é, assumindo o corpo e a palavra como notas colocadas em relação num mesmo plano, Eraritjaritjaka resulta num belíssimo concerto de câmara para um actor. Em cena, o Quarteto de cordas Mondriaan (Amsterdão) interpreta maioritariamente compositores do século XX (inclusivé, o próprio Goebbels) e o actor francês André Wilms, que dá voz às palavras poéticas, ensaistas e diarísticas do Nóbel Élias Canetti (1905-1994).

"Considerações de um intelectual na sua vida pública e privada" poderia igualmente servir de subtítulo a este espectáculo, na medida em que a dicotomia público/privado, tanto das palavras quanto do homem, se materializa por meio do dispositivo cénico principal: a casa, lugar habitado pelo indivíduo e museu da obra do 


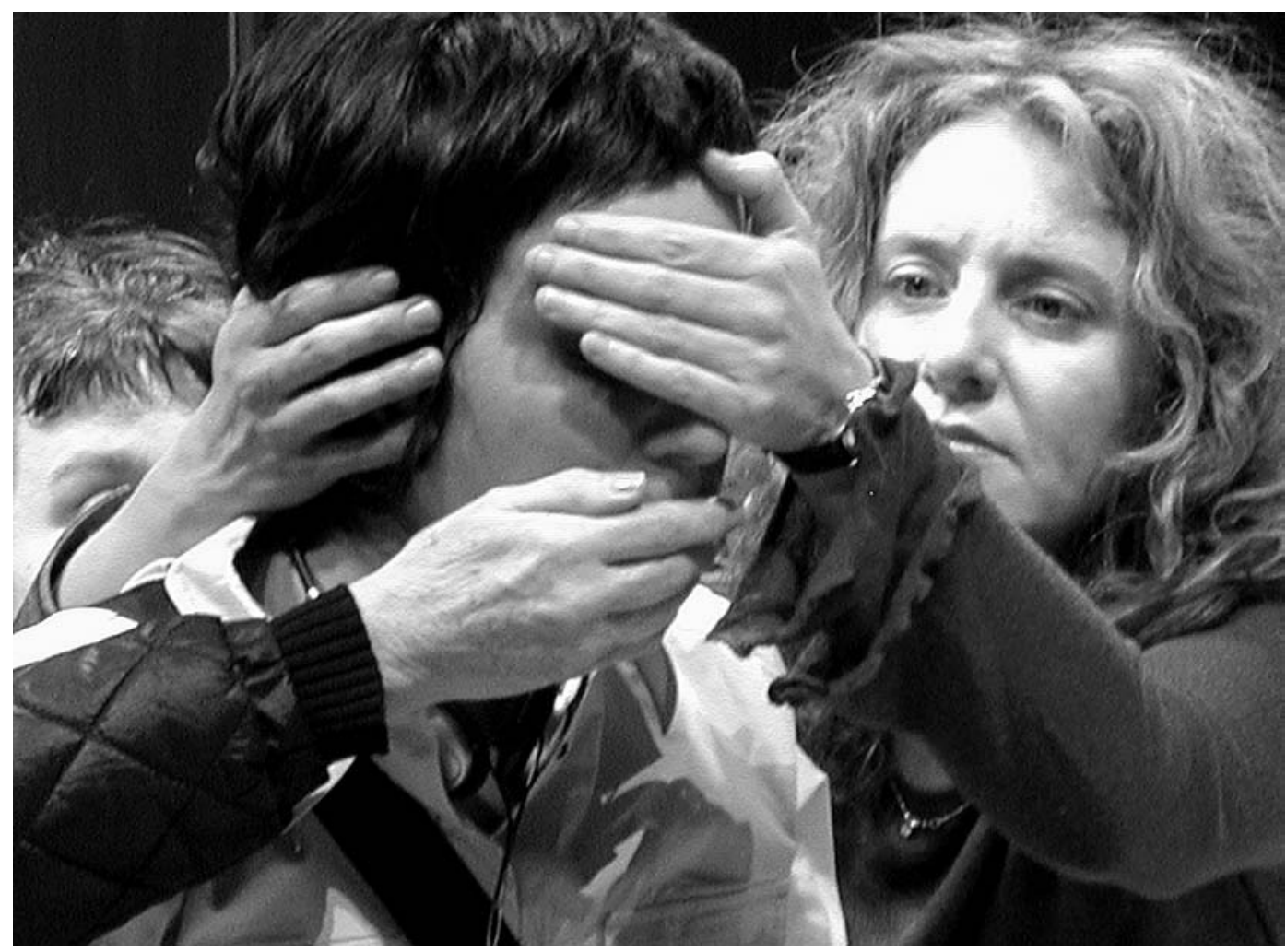

Incendies,

texto e enc. Wajdi

Mouawad,

Abé carré cé carré,

Quebeque, 2006

(Éric Bernier,

Gérald Gagnon,

Reda Guerinik,

Andrée Lachapelle,

Marie-Claude LAnglois,

Isabelle Leblanc,

Julie McClemens,

Richard Thériault

e Isabelle Roy),

fot. Yanick MacDonald.

autor. Da implícita homenagem a Canetti, destaca-se o artifício tecnológico que, exemplarmente, cria esta dinâmica: a partir de determinado momento, o realizador belga Bruno Deville filma ao vivo André Wilms, cuja imagem se projecta numa imensa casa de cenário, criando uma sensação de maior intimidade com a figura do actor. De repente, este abandona o palco e vêmo-lo nos corredores, a sair do teatro, a entrar num táxi e, finalmente, num pequeno apartamento das ruas do Quebeque, mas apenas na projecção. 0 efeito produzido é absurdamente desconcertante. Com a pergunta simples "onde está o actor?", gerada no público, Goebbles não só actua no plano da relação palco/plateia, tão cara aos experimentais anos 70, mas também o reelabora brilhantemente, integrando a tecnologia no espectáculo ao serviço do conceito teatral e não o contrário. Para prová-lo, a reaparição de Wilms. Depois de um longo momento em que o observamos na tela, na intimidade do lar, reencontramo-lo de novo no palco, imprevisivelmente ao lado do quarteto, que havia saido para os bastidores afim de se juntar ao actor, no interior da casa, pensávamos nós, só cenário. Assim, afinada com a clave da partitura, a estratégia dramatúrgica faz mergulhar também o espectador numa ambiguidade insidiosa entre as esferas do público e do privado.

Por último, gostaria de fazer referência a um espectáculo quebequense, escrito e encenado pelo libanês Wajdi Mouwad, residente em Montréal há mais de uma década, tendo feito a sua formação teatral já no Canadá. Incendies coloca em cena a história trágica de uma mulher (quebequense de origem libanesa) que se fecha num silêncio patológico nos últimos anos de vida. Os seus filhos gémeos desenterram a verdade das violências passadas nos conflitos do Médio-Oriente, num bem urdido enredo de inspiração edipiana. À semelhança de outros espectáculos do mesmo autor, que tem vindo a ser premiado desde 1998, Incendies teve uma recepção enfática da crítica e do público em geral. No entanto, para alguém com um background teatral europeu, o espectáculo deitava tudo a perder pelo registo enfadonho das interpretações: melodramático, gritado, redundante. Numa palavra, antigo. Aquilo que me leva a referir-me a ele prende-se com a pergunta que trouxe comigo relativamente à possibilidade de recepção justa de um espectáculo culturalmente específico.

Depois do espectáculo despontou uma discussão, bem internacional, sobre a questão da representação. E, digase, entre europeus e canadianos não foi possivel consenso, nem sobre a pertinência do estilo adoptado, nem sobre qual o nome que melhor o define. Em sintese e apesar de muitas oscilações terminológicas, os europeus defendiam que o espectáculo teria como base o modelo europeu correspondente ao teatro realista (com réstias de declamação e psicologismos); por sua vez, os canadianos reivindicavam um outro realismo, mais poético, para o registo adoptado, com base no modelo americano. Embora não concordando com esta argumentação, pois não é evidente que no realismo stanislavskiano de Lee Strasberg resida a diferença do teatro americano, não pude deixar de reabrir, honestamente, a questão: a diferença de critério estético é absoluta ou relativa, dependendo apenas do ponto de vista cultural implicado em cada espectador (e nem sequer se considera aqui a nacionalidade do encenador!)? Admitindo que é relativa, será possivel, então, uma crítica rigorosa e justa no plano internacional?

Referência bibliográfica

GUAY, Hervé (2005), "Le Miroir vole en éclats: Une décennie de québécois" in Franchir le mur des langues, Montréal, Éditions du Canal, pp. $147-155$. 